\title{
Phytopathology
}

\section{How Does Phytophthora infestans Evade Control Efforts? Modern Insight Into the Late Blight Disease}

\author{
Wiphawee Leesutthiphonchai, Andrea L. Vu, Audrey M. V. Ah-Fong, and Howard S. Judelson ${ }^{\dagger}$
}

Department of Microbiology and Plant Pathology, University of California, Riverside 92521.

Accepted for publication 19 May 2018.

\begin{abstract}
The infamous oomycete Phytophthora infestans has been a persistent threat to potato and tomato production worldwide, causing the diseases known as late blight. This pathogen has proved to be remarkably adept at overcoming control strategies including host-based resistance and fungicides. This review describes the features of $P$. infestans that make it such a daunting challenge to agriculture. These include a stealthy lifestyle that helps $P$. infestans evade plant defenses, effectors that suppress host defenses and promote susceptibility, profuse sporulation with a short latent period that enables rapid dissemination, and a genome structure that promotes the adaptive evolution of $P$. infestans by fostering genetic diversity. Nevertheless, there is reason to be optimistic that accumulated knowledge about the biology of $P$. infestans and its hosts will lead to improved management of late blight.
\end{abstract}

Phytophthora infestans has played a central role in plant pathology as a model for studies of epidemiology, disease management, and molecular plant-microbe interactions. Infamous due to its role in the Irish potato famine, this oomycete remains the most costly pathogen of potato and is a significant tomato pest. One study places the annual cost of potato late blight at $\$ 10$ billion in today's dollars, with chemical control representing 10 to $20 \%$ of the total cost of production (Haverkort et al. 2009). Managing late blight is an ongoing challenge despite improvements in grower education, sanitation, chemical control, and knowledge of the pathogen and host. This review focuses on the features of $P$. infestans that make it a formidable pathogen.

\section{A LIFE CYCLE SUITED TO DISSEMINATION}

Most infections during a season are initiated by asexual sporangia (Fig. 1). Sporangia can germinate directly, or indirectly by cleaving their multinucleate cytoplasm into mononucleate zoospores. These swim across or toward host tissue, upon which encystment occurs.

${ }^{\dagger}$ Corresponding author: H. S. Judelson; E-mail: howard.judelson@ucr.edu

First and second authors contributed equally to this work.

Funding: This work was funded by the National Institute of Food and Agriculture of the United States Department of Agriculture grant 2016-67013-24815, the National Science Foundation, and the Division of Molecular and Cellular Biosciences grant 1616339.

(C) 2018 The American Phytopathological Society
Each cyst then extends a germ tube which can enter leaves and stems through stomata, but more often forms an appressorium that breaches the cuticle and epidermal cell wall. Tuber ingress occurs mainly through buds, wounds, or natural openings such as lenticels. Growth within the plant primarily involves the extension of intercellular hyphae, which insert haustoria into host cells. As a hemibiotroph, $P$. infestans only infects living tissue, extracting nutrients from the apoplast or extrahaustorial space for most of the disease cycle. The terminal stage of infection is associated with sporulation and host necrosis.

Sporulation is timed to optimize disease spread. Sporulation can occur as soon as 3 to 4 days after infection, depending on environment and the genotypes of the pathogen and host. Each lesion can produce several hundred thousand sporangia, with new spores formed daily for several days. Several infection cycles can occur within 2 weeks, resulting in the destruction of an entire field (Fry et al. 2015). Postharvest losses can also occur, for example during potato storage if conditions are too humid.

$P$. infestans sporulates when the environment is favorable for propagating the disease. Sporulation requires high humidity and is suppressed by light, and thus occurs primarily during night (Bashi et al. 1982; Xiang and Judelson 2014). This enhances the survival of sporangia, because they are hydrated and hyaline and thus prone to death through desiccation or UV damage (Mizubuti et al. 2000); in contrast, fungal spores typically contain UV-blocking pigments and are desiccated. Light-sensitive transcription factors have been identified that regulate $P$. infestans sporulation (Xiang and Judelson 2014). The primary light receptors are believed to be cryptochromes, which also play roles in light perception in animals and plants. Once sporulation is triggered, sporangiophore initials appear 
(emerging from stomata on foliage), followed within 6 to $7 \mathrm{~h}$ by sporangia (Maltese et al. 1995).

That sporulation occurs late at night also enhances the escape of sporangia from the plant canopy. Mature sporangia are deciduous, allowing dispersal by wind or water (Granke et al. 2009). Declining humidity after sunrise causes sporangiophores to hygroscopically twist and fling sporangia into the air (Hirst 1953). Aided by wind, sporangia have been found to travel up to 10 to $20 \mathrm{~km}$ in less than $3 \mathrm{~h}$ (Aylor 2003). Long-distance dispersal is aided by their dragreducing elongated shape (Roper et al. 2008).

The suppressive effect of light on sporulation is common to most foliar Phytophthora pathogens. In contrast, light stimulates sporulation in most root-infecting species (Harnish 1965). This causes the latter to sporulate on "unearthed" plant parts such as crowns, from which spores can move to new hosts. The divergent responses to light by leaf and root colonizers are adaptations linked to each of their niches.

Zoospores are potent propagules. These increase the range of colonization beyond where sporangia land. Zoospores can swim a few centimeters through wet soil leading to tuber infection, in addition to traveling farther through rain or irrigation water (Porter et al. 2005). On leaves, penetration occurs preferentially next to guard cells (Gees and Hohl 1988). Whether this benefits the pathogen is unknown, but it is assumed that zoospores home in on that site using chemotaxis. The importance of chemotaxis in root infection by other Phytophthora is well-documented (Walker and van West 2007), but more research is needed to understand the role of chemotaxis in P. infestans.

Zoospore release from sporangia requires free water and cool temperatures, and it is probably no coincidence that sporangia mature during late evening when dew is likely to be on foliage and temperatures are low. Zoosporogenesis can occur within minutes and is one of the most rapid developmental processes known in any species. Cold is sensed by the sporangium as increased membrane rigidity, which probably regulates intracellular signaling molecules (Tani and Judelson 2006). Binding sites for a temperature-sensitive transcription factor have been identified upstream of zoosporogenesis-activated genes. However, these genes are more likely to participate in cyst germination, since inhibitor studies show that all proteins needed to make zoospores are present in sporangia. RNA profiling studies identified genes encoding flagellar proteins as among the earliest to be transcribed during sporulation (Ah-Fong et al. 2017a; Judelson et al. 2009). Sporangia are accordingly primed to release zoospores and require only a narrow temporal window to initiate infections.

Zoospores can swim for up to $24 \mathrm{~h}$, although encystment usually occurs more quickly. Energy for the ATP-intensive swimming stage likely comes from lipid metabolism (Walker and van West 2007). Taurocyamine kinases also help store energy and shuttle highenergy phosphoryls from mitochondria to flagella (Kagda 2017). This is analogous to the creatine kinase system of vertebrates, which stores energy for use during muscle exertion.

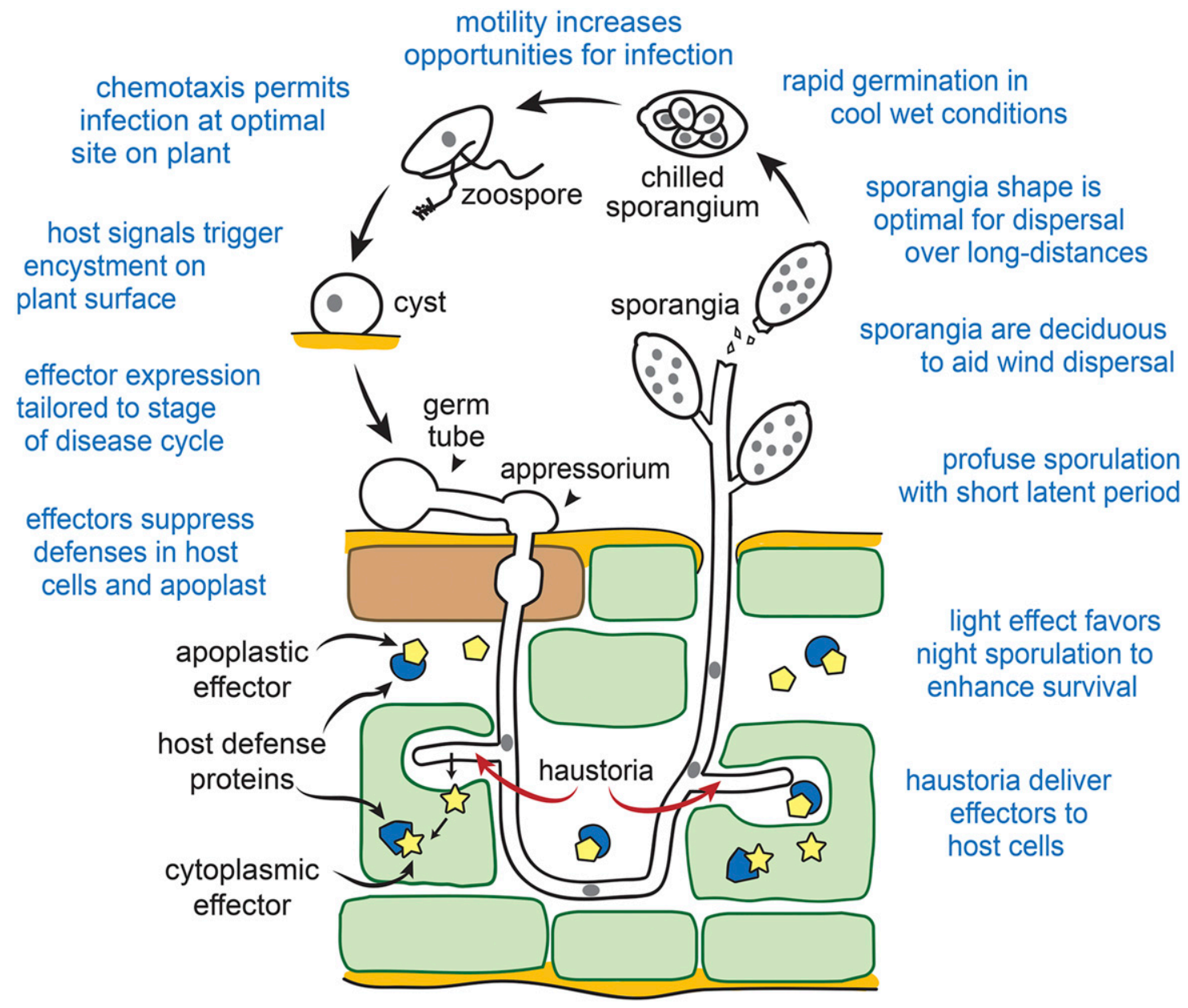

FIGURE 1

Disease cycle of Phytophthora infestans on foliage, with features that contribute to its pathogenic success highlighted. While the diagram illustrates the infection of foliage, tubers can also play an important role by serving as a pathogen reservoir between seasons. The cycle can also occur on tubers during storage. 


\section{DIVERSE SOURCES OF INOCULUM}

Airborne spores represent just one route by which late blight can spread to a potato or tomato field. $P$. infestans can also be transmitted in seed, from a soil reservoir of sexual spores, and from alternative hosts. In areas where winter soil temperatures are not cold enough to kill infected tubers left in the field, sprouts emerging in the following growing season may also serve as sources of inoculum.

Importation on seed. $P$. infestans has been well-served by its specialization to potato as a host. More than 150 years since it escaped its ancestral home in Mexico, this pathogen can still rely on humans to spread the disease. Cultivated potato (a tetraploid) is grown from seed tubers, which are ideally produced in low-disease regions and screened for late blight. However, many developing countries lack seed certification programs. Furthermore, some degree of infection is tolerated by most certification programs, allowing inoculum to be distributed to otherwise disease-free areas. This type of dissemination is suspected when new genotypes of the pathogen in one geographic region resemble those found elsewhere. For example, trade in seed tubers appears to be responsible for the spread of the aggressive Blue_13 lineage from Europe to Asia (Chowdappa et al. 2013; Li et al. 2013). The dynamics of seed tuber transmission are complex since much blighted seed may not survive to produce infected sprouts.

The use of seed tubers has been assumed to be necessary for high yields, but this has been challenged in a proposal to shift the potato industry to true diploid seed, which should be less likely to transmit late blight (Jansky et al. 2016). The disease could still be spread on transplants, as in 2009 when $P$. infestans disseminated on tomato caused a pandemic in the eastern United States. Late blight can also be spread on crops grown for consumption. This occurred in the 1980s when new lineages spread on potato from Mexico to Egypt and then Europe (Fry et al. 2015). Tomato fruit also enables dispersal when symptomless infected fruits harvested at one location are shipped to a distant repacking house, and then are discarded in an open trash container or compost pile once symptoms appear.

Oospores are a multiyear threat. These thick-walled spores result from sexual reproduction between $\mathrm{A} 1$ and $\mathrm{A} 2$ mating types (Judelson 2007). Oospores can persist for years in soil, surviving freezing and fungicides (Duncan 1985; Turkensteen et al. 2000). This distinguishes oospores from sporangia which are short-lived, and hyphae which survive poorly apart from the host. Oospores also germinate more sporadically than sporangia. Thus, a population of oospores formed one year can threaten plantings over multiple years. In regions of northern Europe and Mexico where sexual reproduction of $P$. infestans is frequent, oospores are an important source of inoculum (Grünwald and Flier 2005; Lehtinen and Hannukkala 2004). Oospore-driven disease tends to occur earlier in the season than sporangium-driven disease, and often appears lower on the plant where detection by scouting is more difficult (Andersson et al. 1998).

At one point, only the A1 mating type was widespread outside of Mexico, but now both A1 and A2 strains occur in most regions. Nevertheless, sexual reproduction is not very common in most regions. This may be because A1 and A2 strains are not found at the same location at the same time, are not adapted to the same host, or are genetically incompatible (Danies et al. 2013). Infrequent matings are nevertheless significant as this generates new pathogen genotypes. Chemical stress has also been reported to induce oospores, although whether these are viable is unknown (Groves and Ristaino 2000).

Self-fertile strains may be an emerging inoculum. Genetic models predict that crosses should yield a 1:1 ratio of A1 and A2 types. However, laboratory and field studies have also identified self-fertiles, which produce oospores in single culture and may be A1-A2 heterokaryons or contain extra copies of the mating type locus (Judelson 1996). Self-fertiles have now been described on multiple continents, and continued monitoring of this situation is needed due to their potential impact on disease management. Many self-fertiles in China were reported to be more fit than normal strains (Zhu et al. 2016).

Alternate hosts as refuges. Besides potato and tomato, $P$. infestans colonizes other members of the family Solanaceae including wild hosts such as Solanum dulcamara and S. sarrachoides (bittersweet and hairy nightshades) and petunia. These can harbor the pathogen between or during another crop's growing seasons. Many isolates from the Americas and Europe are pathogenic and able to form oospores on the wild hosts, which often grow near commercial fields (Dandurand et al. 2006; Frost et al. 2016). Even if a $P$. infestans strain is better-adapted to a cultivated host, lineages that are equally pathogenic on cultivated and wild hosts could arise through matings or mutation. Knowledge of the role of the wild hosts is limited and would benefit from population studies of isolates from each source. A worrisome observation is that $P$. infestans was found to survive several days of freezing in infected berries of $S$. sarrachoides (Dandurand et al. 2006; Frost et al. 2016).

\section{EVADING AND SUPPRESSING HOST DEFENSE}

P. infestans is a stealthy pathogen. Its modus operandi for most of the disease cycle is to minimize damage to the plant, while suppressing the host immune response. Defeating the defenses and maintaining host cell integrity is essential since $P$. infestans can only feed from living cells in its biotrophic stages.

Plants have several layers of active defense (Zipfel 2014). The first involves the detection of pathogen-associated molecular patterns (PAMPs) by pattern recognition receptors (PRRs). Examples of oomycete PAMPs are arachidonic acid and the Pep13 transglutaminase that resides in the cell wall (Brunner et al. 2002). Detection of a PAMP causes pattern-triggered immunity (PTI) in which defense gene activation leads to the production of antimicrobial substances. Similar responses are caused by damageassociated molecular patterns (DAMPs) that are generated by the pathogen, such as host wall fragments. Many pathogens including $P$. infestans overcome PTI by delivering defenseblocking effectors to the plant. In turn, plants have evolved to detect some effectors, leading to effector-triggered immunity (ETI) which involves programmed plant cell death. P. infestans has several strategies for muting each of these defense mechanisms.

Apoplastic effectors block plant enzymes. Plants secrete serine proteases, cysteine proteases, and $\beta$-1,3-glucanases into the apoplast to battle their pathogens, and as a counter-defense $P$. infestans secretes inhibitors of such enzymes (Raffaele et al. 2010a). One example is cysteine protease inhibitor EPIC1. Interestingly, $P$. infestans EPIC1 functions best against potato and tomato proteases, while orthologs in the sister species $P$. mirabilis are adapted to proteases of its host, Mirabilis jalapa (Dong et al. 2014). $P$. infestans and $P$. mirabilis have evolved recently from a common ancestor, and it appears that their proteins have adapted to their respective hosts.

$P$. infestans also secretes enzymes that may help suppress or evade other plant defenses. These include glycoside hydrolases which may degrade phytoalexins, isochorismatases which may interfere with salicylic acid signaling by the host, and berberine bridge enzymes (Liu et al. 2014; Raffaele et al. 2010a). The latter may deactivate oligosaccharides that might otherwise function as DAMPs (Daniel et al. 2017).

Apoplastic growth helps evade plant perception. While epidermal cells are usually penetrated by $P$. infestans at the onset of leaf infection, subsequent growth during the biotrophic stage is restricted to the apoplast. By limiting damage to host cells, this 
strategy may help $P$. infestans evade detection. Also contributing to ability of $P$. infestans to dodge host defenses is the fact that its cell wall lacks chitin, which is a major PAMP used by plants to detect fungi. Some defense suppression may still be needed since P. infestans produce other PAMPs such as Pep-13.

Haustoria formation may appear to be very disruptive to the plant, but the openings made in the mesophyll wall are only a few microns in diameter which may limit DAMP generation. Also, the integrity of the host plasmalemma is maintained as it becomes converted into the extrahaustorial membrane (EHM). Many host proteins are excluded from the EHM including PRRs, which should also limit the ability of the plant to detect $P$. infestans (Lu et al. 2012). The EHM is where effectors are translocated into the host, together with the extrahaustorial matrix which is likely of both plant and pathogen origin. Haustoria may also be used to acquire nutrients. By extracting nutrients from the EHM or apoplast, P. infestans may minimize metabolic perturbations that could trigger the immune response (Zeier 2013). Whether some $P$. infestans effectors influence host transporters to deliver nutrients to the apoplast would be worth investigating, as this has been observed in other pathosystems with sugar transporters of the SWEET family (Streubel et al. 2013).

Suppression by cytoplasmic effectors. Two families of proteins, RXLRs and CRNs, dominate the $P$. infestans secretome. RXLRs are named after an amino acid motif near their N-termini, and CRNs after a "crinkle and necrosis" phenotype observed when overexpressing some members of the family in a plant. A typical $P$. infestans genome is predicted to encode about 560 RXLRs and 190 CRNs, although not all are expressed at measurable levels (Ah-Fong et al. 2017b). Members of both families are secreted and translocated into plant cells. They are delivered to the plant primarily through haustoria, with some traveling in extracellular vesicles (Wang et al. 2017).

Once in plant cells, RXLRs promote disease by either inhibiting defense pathways or stimulating susceptibility factors. The specificity of each effector is determined by a core fold that varies in sequence and tandem repeat size (Win et al. 2012). Examples of targets include components of the plant secretory and autophagy systems, the plant small RNA processing machinery, and numerous regulators including protein phosphatases and kinases, histonemodifying proteins, and transcription factors. The list of RXLR targets is lengthy and readers are referred to recent reviews on the subject (Boevink et al. 2016; Sharpee and Dean 2016). Some CRNs also bind plant proteins used for defense, but most target nuclei where they reprogram gene expression to raise susceptibility (Song et al. 2015). Since multiple targets are affected by RXLRs and CRNs, a single mutation in the plant is unlikely to lead to resistance.

Orchestrated deployment of the effector arsenal. In addition to the proteins described earlier, the effector complement of $P$. infestans includes proteases and at least 11 types of cell wall degrading enzymes (CWDEs) such as pectate lyases, polygalacturonases, xylanases, and others. Most effector families are expressed in temporal waves during colonization. A simpler pattern would be insufficient to block the multiple layers of plant immunity and influence other features of host physiology that may help $P$. infestans acquire nutrients. Some effectors are under developmental control and induced in sporangia, zoospores, or germinated cysts. Others are expressed at different stages of in planta growth, possibly in response to plant signals or stress (Ah-Fong et al. 2017a). The net effect is to balance the needs of $P$. infestans against the risk of excessively perturbing the host.

Toward the end of the disease cycle, the nature of $P$. infestans growth changes. Haustoria are no longer formed, host cells become necrotic, and some hyphae grow through plant cells rather than being limited to the apoplast. Unknowns at this stage include the extent of nutrient acquisition from lysed cells, and whether host necrosis is caused actively or passively by $P$. infestans. One hypothesis is that hyphae within the necrotic zone are vacuolated and thus unable to block the plant immune response. However, the fact that $P$. infestans expresses the host necrosis-inducing NEP1 proteins during late infection suggests that death is a deliberate outcome that may release a final burst of nutrients to the pathogen. Evading host defenses is apparently pointless once the pathogen has committed to escaping through sporulation.

Comparisons with Pythium. Data from a comparison of potato tubers colonized by $P$. infestans or the necrotroph Pythium ultimum (potato leak pathogen) yields insight into biotrophic and necrotrophic lifestyles (Ah-Fong et al. 2017b). One major difference is the absence of most if not all RXLRs and CRNs from Pythium ultimum, which uses host cell death as its infection strategy. Pythium ultimum also encodes more secreted proteases than $P$. infestans. The two species otherwise exhibit few differences in gene content, with the major dissimilarity being how their genes are expressed. For example, CWDE and protease expression are elevated in Pythium ultimum compared with $P$. infestans during early tuber infection. In addition, NEP1 toxins that are expressed primarily during late infection by $P$. infestans are made during early colonization by Pythium ultimum; oomycetes evade death by these toxins since they are specific for sphingolipids found in dicots (Lenarcic et al. 2017).

There are also many differences in the defensive enzymes produced by the two pathogens. For example, P. infestans induces its secreted catalases during the biotrophic phase, presumably to eliminate toxic peroxides made by the host. In contrast, Pythium ultimum catalases are expressed at low levels, suggesting that peroxide elimination is not critical to its lifestyle. In fact, Pythium ultimum turns on several secreted NADPH oxidases during tuber infection, which generate superoxide that may damage and trigger programmed cell death in the host.

\section{EVADING HOST RESISTANCE GENES}

The history of breeding for resistance in potato illustrates the ability of $P$. infestans to evade man's efforts at control. Programs early in the twentieth century concentrated on major dominant resistance $(R)$ genes from the wild species $S$. demissum. Eleven genes were introgressed into potato with several individual genes moved into cultivars, but all succumbed to late blight soon thereafter. Subsequent attempts to pyramid $R$ genes looked promising initially but success was short-lived. For example, the European variety Pentland Dell, bearing $R 1, R 2$, and $R 3$, seemed immune to late blight when released in 1961, but resistance broke down in 1967 (Malcolmson 1969). Dutch cultivars also became susceptible within a decade of being introduced (Turkensteen 1993).

Basis of resistance-breaking. One can imagine the frustration of breeders in the early days, when Flor's gene-for-gene concept was unknown and later when the molecular determinants of resistance and resistance-breaking were still undefined. Most $R$ genes are now known to encode nucleotide-binding site leucine-rich repeat receptors (NLRs), which recognize pathogen avirulence proteins, which in oomycetes are usually RXLRs. For example, resistance is triggered when R3a detects Avr3a ${ }^{\mathrm{KI}}$, but not when the $P$. infestans strain expresses its Avr $3 \mathrm{a}^{\mathrm{EM}}$ variant. In the absence of R3a, Avr3A benefits $P$. infestans by stabilizing potato ubiquitin ligase that contributes to PTI (Bos et al. 2010).

A related mechanism allows isolates to evade recognition by the $R B$ gene, also known as Rpi-blbl. The discovery and cloning of $R B$ was heralded as a major advance since it conferred resistance against a broad spectrum of $P$. infestans isolates (Halterman et al. 2008). However, strains that are not controlled by $R B$ have since been identified, although they are not yet widespread. $R B$ recognizes the RXLR known as IPI-O, which varies in family size and sequence between isolates (Halterman et al. 2010). Resistance is elicited by IPI-O1 and IPI-O2 subtypes of the protein, but not by IPI-O4. Moreover, IPI-O4 suppresses IPI-O1-elicited resistance. 
Studies of diverse isolates reveal that extensive sequence polymorphism is common and extends beyond Avr3a and IPI-O. RXLRs also exhibit copy number variation, with paralogs duplicated or missing in some isolates (Yoshida et al. 2013). Does this suggest that long-lived resistance using NLR genes is unachievable, since the use of any $R$ gene will select for resistance-breaking variants of the pathogen? Hopefully, understanding the nature of pathogen variation will lead to improved strategies for $R$ gene deployment.

\section{EVADING CHEMICAL CONTROL}

The use of chemicals against $P$. infestans dates to the 19th century with Bordeaux mixture. In the absence of durable plantbased resistance, chemicals remain a key tool against late blight, with multiple protectant and systemic chemistries in use. In recent years, over 5 million pounds of active ingredient have been employed against late blight annually in the United States. However, several issues allow $P$. infestans to evade or reduce their effectiveness. DMI (demethylation inhibitor) fungicides developed for fungi are not useful, since $P$. infestans does not synthesize sterols (Dahlin et al. 2017). There are several potent oomycete-specific systemics, but applications per season are often limited to prevent selecting for resistant strains. Since $P$. infestans hyphae are shielded within plant tissue, nonsystemics must be applied prophylactically with good foliar coverage, but this may be difficult or not economically sustainable. Protecting underground tubers also remains a challenge. As with $R$ genes, the durability of an oomyceticide needs to be tested over long periods in diverse locations.

Protective mechanisms. Several processes help protect $P$. infestans from toxicants. One response that is shared by most eukaryotes is the induction of ATP-binding cassette (ABC) transporters, which pump chemicals out of cells. In P. infestans, oomyceticides were found to increase the expression of several ABC transporters (Judelson and Senthil 2006). Continued exposure to metalaxyl was also shown to upregulate $A B C$ transporters by what appeared to involve epigenetic control, a semi-heritable process that involves chromatin modification (Childers et al. 2014).

Sensitivity can also be reduced by slowing uptake of the chemical, and this was suggested to occur in response to metalaxyl through changes in plasma membrane composition (MariduenaZavala et al. 2017). Another protective response is upregulating the pathway targeted by the chemical, as described in Phytophthora for pyrimorph (Pang et al. 2015). P. infestans also expresses $\mathrm{P} 450$ monooxygenases and glutathione-conjugating enzymes that have been implicated in degrading crop protection chemicals. These same enzymes may have evolved to protect $P$. infestans against phytoalexins.

Variation in baseline sensitivity. Because of differences in the chemical's protein target and in protective mechanisms such as those described above, variation can occur between isolates in their baseline sensitivity, which refers to populations not yet exposed to the chemical. This is important since the concentration used to protect crops must inhibit the least-sensitive member of the pathogen population. Up to 10 -fold variation between isolates were detected against eight compounds including azoxystrobin, cymoxanil, and others in surveys of isolates from the center of genetic diversity of $P$. infestans in Mexico, and from North America (Grünwald et al. 2006; Saville et al. 2015).

Deploying a chemical against $P$. infestans would be expected to select for strains reduced in sensitivity by enriching for pre-existing or new genetic variants. A single-season field test of seven chemistries against $P$. infestans demonstrated that this occurred to a minor extent with cymoxanil but more with metalaxyl (Grünwald et al. 2006). This can be related to recent experience in the United
States, where metalaxyl use seems to have selected for strains reduced in sensitivity in clonal lineages that were previously very sensitive (Matson et al. 2015; Saville et al. 2015).

Target site mutations. A downside to systemics is that they usually have a single target, which can mutate to evade control. This was first observed in Phytophthora with metalaxyl, including its $\mathrm{R}$-isomer mefenoxam. Soon after being introduced in the 1970s, resistant strains appeared in several locations (Davidse et al. 1981). Initial studies predicted that resistant strains would be less fit, but this proved to be untrue and resistance was detected in isolates collected prior to commercial use of metalaxyl (Daggett et al. 1993). Metalaxyl insensitivity is a complex trait. Segregation analysis indicated that insensitivity acts like a quantitative trait involving major and minor loci, with the latter potentially including genes such as ABC transporters (Judelson and Roberts 1999). Sequence polymorphisms in a subunit of RNA polymerase I were inferred to contribute to resistance in some isolates, which is logical since metalaxyl blocks ribosomal RNA synthesis (Randall et al. 2014). However, this locus was shown to not determine resistance in other isolates, supporting the idea that several major sensitivity loci may exist (Matson et al. 2015).

Control failures due to resistance have also been reported for fluazinam, an uncoupler of oxidative phosphorylation introduced in The Netherlands in 1992. This chemical acts by moving protons across lipid bilayers instead of inhibiting a specific protein target, so the selection of resistant strains was proposed to be unlikely. However, resistance appeared in P. infestans in The Netherlands in 2010, and does not appear to be associated with a fitness penalty (Schepers et al. 2018).

Although not yet described in $P$. infestans, target site mutations in other oomycetes have led to resistance against other chemistries used against late blight. These include the $\beta$-tubulin inhibitor zoxamide, the cellulose synthase inhibitor mandipropamid, and oxathiapiprolin, which affects an oxysterol-binding protein (Blum et al. 2010; Cai et al. 2016; Miao et al. 2016). This suggests that $P$. infestans will continue to demonstrate an ability to evade chemical control, necessitating ongoing research into new chemistries or alternative treatments such as biological control.

\section{MECHANISIMS AND BENEFITS OF GENETIC VARIATION}

Pathogens with adaptable genomes are more likely to survive as their hosts and environments evolve, including when humans deploy chemicals and $R$ genes. Processes facilitating change include spontaneous mutation, sexual recombination, variation in gene families, polyploidy, epigenetic events, and horizontal gene transfer (Fig. 2). Such events have helped oomycetes to become plant pathogens, Phytophthora to distinguish itself from Pythium by shifting to a more biotrophic lifestyle, and a $P$. infestans ancestor to jump from a wild Solanaceous host to potato and tomato. When infection is initiated by a single spore, mutations cause $P$. infestans to evolve into a population of diverse genotypes, aided by its short generation time and profuse sporulation. Within that mixed population, some individuals will succeed while others move toward extinction. Application of a chemical may select for the rare mutation that confers resistance, for example. From an ecological perspective, the fact that many genetic variants become failed experiments is of little concern if the species survives.

Phenotypic diversity. Isolates of $P$. infestans vary in many traits relevant to disease. For example, predominating in the United States over the past decade have been several clonal lineages (Fry et al. 2013). Some are more fit on potato than tomato (US8, US24), others are pathogenic on both (US11, US22, US23), and different lineages exhibit low (US22, US23), intermediate (US24), or high insensitivity (US8, US11) to metalaxyl. Some lineages display 
higher rates of sporulation (US23), better cold survival (US23), germination optimized to colder temperatures (US24), and the ability to evade $R$ genes.

In the United States, much of the variation is thought to have been introduced by migration from parts of Mexico where sexual recombination routinely shuffles alleles. Sexual reproduction in North America has been infrequent but yielded new aggressive genotypes such as US8, so even rare events may be significant (Gavino et al. 2000). Most strains now in the United States belong to asexual clonally propagated lineages, as defined using microsatellite markers, but this does not exclude the possibility of variation arising from mutation. Much diversity exists in European populations of $P$. infestans, reflecting the contributions of sexual recombination, mutation, and migration (Mariette et al. 2016).

One of the complications caused by pathogen diversity is that many management tools are optimized to a generic model of $P$. infestans biology, including sensitivity to chemicals, latent period, and germination conditions. Software has been developed for decision-making that takes into account some characteristics of the pathogen (Small et al. 2015). This should help when the phenotype of the pathogen is known, but would have less value when outbreaks involve diverse populations.

Genome architecture encourages variation. Most Phytophthora species have sizeable, repeat-rich genomes. P. infestans has one of the largest at $240 \mathrm{Mb}$, with $74 \%$ of its genome comprised of sequences related to transposable elements and other repeats (Dong et al. 2015). Genes for effectors including RXLRs and CRNs reside disproportionately in gene-poor, repeat-rich regions, which may tolerate more nonallelic recombination and other forms of structural variation. Genes in these zones are also more likely to exhibit positive selection, which refers to an excess of base changes that alter the corresponding amino acid (Raffaele et al. 2010b). This observation led to the

FIGURE 2

Mechanisms leading to genetic variation in Phytophthora infestans.

Illustrated clockwise from the top are sexual recombination during oosporogenesis; polyploidy resulting from nondisjunction; gene deletion due to intrachromosomal recombination; epigenetic silencing; disruption of a gene by a DNA transposon; expansion of a gene family

by unequal crossing-over followed by a sequence change through mutation; horizontal gene transfer; and mutation resulting in sectoring within a lesion. These events may occur over short or long evolutionary timescales. "two-speed genome" model in which the repeat-rich zones support the rapid evolution of effectors, facilitating gains in virulence and other changes that benefit the pathogen (Dong et al. 2015).

Horizontal gene transfer (HGT) has contributed to fitness. The acquisition of foreign genes can allow the recipient to gain new lifestyles or exploit a new niche such as a plant host. As many as 48 genes obtained by HGT may contribute to oomycete biology, with 33 acquired after Phytophthora, Pythium, and downy mildews diverged from other oomycetes (Savory et al. 2015). Most of these genes have come from fungi and bacteria, and encode enzymes involved in degrading the plant cell wall or cuticle such as polygalacturonases. HGT genes also include many involved in metabolism and nutrient import, including sugar and purine transporters, lipases, and sugar alcohol dehydrogenases. The NEPI necrosis-inducing protein also appears to be obtained by HGT (Gijzen and Nurnberger 2006).

Interestingly, there is more evidence of HGT in Phytophthora than in its necrotrophic or biotrophic relatives. Mechanisms leading to HGT are unknown, but Phytophthora genomes may be more receptive to insertions than average since events in their more-abundant repeatrich regions would be unlikely to disrupt existing genes. That the major sources of HGT loci, fungi and bacteria, occupy niches that overlap with oomycetes is not surprising. P. infestans has been shown to be receptive to gene transfer from Agrobacterium, but how fungal genes were obtained is less obvious (Wu et al. 2016). Phytophthora is not known to undergo anastomosis and it seems unlikely that its cellulosic cell wall could fuse with the chitinous wall of fungi, but vectoring through a virus is a possibility. Foreign DNA may also possibly be taken up directly, especially by the wall-lacking zoospores.

Gene families enable diversification. Gene duplication is an important mechanism for creating novelty and can result from unequal crossing over, transposition, or chromosomal
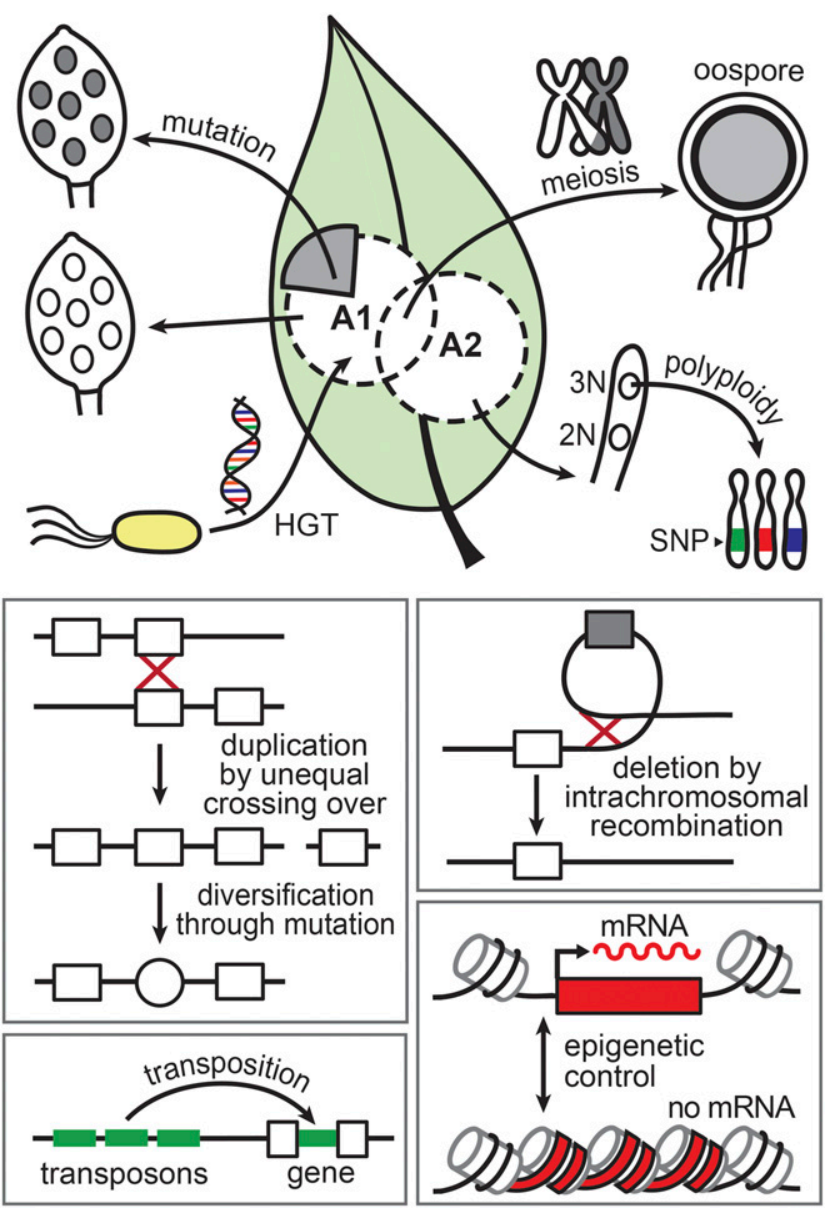
rearrangements. Duplication provides genetic material for mutation and selection to act upon, resulting in new or specialized functions. About half of the ca. 18,000 genes in P. infestans belong to families that range in size from 2 to $>100$ copies. These include genes encoding proteins involved in central metabolism, effectors such as RXLRs and CRNs, and ABC transporters, and a majority of HGT loci.

RXLRs have taken multiple evolutionary paths including expansions or contractions of their protein interaction domains, recombination between paralogs, selection of point mutations, and deletion (Goss et al. 2013). Such changes could allow P. infestans to escape recognition by an $R$ gene. Other changes could help $P$. infestans infect new host genotypes. Whole-genome sequence analysis has revealed that unlike housekeeping genes, effector genes frequently vary in copy number, and many have been pseudogenized. One study detected transcripts during early infection from only 245 of the $>500$ predicted RXLRs in any of five strains being tested, and only 108 in all five strains (Yin et al. 2017). A global study of $P$. infestans gene families found no correlation between family size and their aggregate level of expression (Ah-Fong et al. 2017b).

Polyploidy is common. P. infestans is regarded as a diploid, but analyses based on microfluorometry and single nucleotide polymorphism (SNP) allele frequencies identify diploid, triploid, and tetraploids in natural populations as well as trisomics, i.e., 2N+1 (Li et al. 2017; Yoshida et al. 2013). A trend has been for diploids to predominate in sexual populations and asexual pandemic lineages to involve triploids, although the strain linked to the Irish Famine, HERB1, was diploid. Changes in ploidy could result from errors in chromosomal replication or segregation, including unreduced gametes.

Polyploidy yields several potential benefits, such as buffering mutational load by masking deleterious alleles, allowing more freedom to generate alternative alleles, and enabling more genetic diversity to be maintained. Polyploidy may also foster the accurate mending of double-strand DNA breaks caused by UV or chemicals by providing more templates for homologous recombination-based repair, instead of the error-prone process of nonhomologous end joining. Changes in ploidy, including aneuploidy, may also alter gene expression. In fungal animal pathogens, polyploidy has been linked to enhanced fitness and is common in strains exposed to stress (Todd et al. 2017). In contrast, applying stress to $P$. infestans triploids in the laboratory led to a return to diploidy. This would be beneficial if the goal was to increase success in matings by reducing the likelihood of unbalanced gametes (Li et al. 2017).

Epigenetic variation. Plant pathologists have always struggled to explain spontaneous and reversible changes in the virulence of pathogens such as $P$. infestans. The reversible loss of avirulence caused by an epigenetic switch has been described in P. sojae (Qutob et al. 2013) and presumably also occurs in $P$. infestans. Epigenetic processes alter accessibility of the transcriptional machinery to genes through histone methylation and other modifications to chromatin. This state can be inherited for generations, but is more reversible than mutations. Epigenetic events add to the mixed population concept introduced earlier: in addition to stable mutations in an asexual lineage contributing to adaptation, each genotype may occur in multiple epigenetic states.

It is possible that the presence of effector genes in repeat-rich regions of the genome have placed them under control of the same epigenetic processes that silence nearby mobile elements. There is evidence of the historical activity of transposable elements in $P$. infestans, but little indication of current activity. While functional elements may reside in its genome, $P$. infestans expresses small RNAs homologous to transposable elements that may suppress their activity (Vetukuri et al. 2012).

\section{PERSPECTIVE: CAN KNOWLEDGE OF THE PATHOGEN IMPROVE DISEASE CONTROL?}

Understanding how $P$. infestans is detected by $R$ genes and how it evades recognition is already informing strategies for managing late blight. Lessons from resistance breeding have led to an emphasis on stacking $R$ genes by conventional breeding or cisgenesis. For example, the Sarpo Mira variety developed for Europe contains five $R$ genes including one quantitative trait locus (Rietman et al. 2012). Through a strategy dubbed "effectoromics", RXLRs that are conserved in structure and expression between isolates have been identified and used as targets in screens for new sources of resistance in germplasm collections ( $\mathrm{Du}$ and Vleeshouwers 2014). Engineering $R$ genes with new specificities may also be possible (Rodriguez-Moreno et al. 2017). $R$ genes with novel targets may be more durable since natural $R$ genes are the product of plant coevolution with pathogens, which may already have evolved resistance-breaking genotypes. A productive approach may be to shift toward resistance that detects PAMPs, which may be less likely than effectors to vary between isolates. With each approach, vigilance in characterizing diversity within $P$. infestans will still be needed to keep a step ahead of the pathogen.

Monitoring populations will also inform conventional control strategies, by identifying whether strains are sensitive to chemistries and fine-tuning application regimes based on the characteristics of the pathogen. Greater knowledge of the novel features of $P$. infestans metabolism, including horizontally transferred genes that lack plant orthologs, may also provide new targets for chemical control. Extending population genetic studies from isolates from commercial potato and tomato fields to wild hosts will help reveal their importance as refuges for the pathogen, and may provide more data in support of excluding wild species from areas under cultivation. P. infestans has proved to be a cunning pathogen, but more knowledge of its biology should lead to more effective, environmental benign, and economically sustainable control.

\section{ACKNOWLEDGMENTS}

This work was funded by the National Institute of Food and Agriculture of the United States Department of Agriculture, and the National Science Foundation.

\section{LITERATURE CITED}

Ah-Fong, A. M. V., Kim, K. S., and Judelson, H. S. 2017a. RNA-seq of life stages of the oomycete Phytophthora infestans reveals dynamic changes in metabolic, signal transduction, and pathogenesis genes and a major role for calcium signaling in development. BMC Genomics 18:198.

Ah-Fong, A. M. V., Shrivastava, J., and Judelson, H. S. 2017b. Lifestyle, gene gain and loss, and transcriptional remodeling cause divergence in the transcriptomes of Phytophthora infestans and Pythium ultimum during potato tuber colonization. BMC Genomics 18:764.

Andersson, B., Sandstrom, M., and Stromberg, A. 1998. Indications of soil borne inoculum of Phytophthora infestans. Potato Res. 41:305-310.

Aylor, D. E. 2003. Spread of plant disease on a continental scale: Role of aerial dispersal of pathogens. Ecology 84:1989-1997.

Bashi, E., Benjoseph, Y., and Rotem, J. 1982. Inoculum potential of Phytophthora infestans and the development of potato late blight epidemics. Phytopathology 72:1043-1047.

Blum, M., Waldner, M., and Gisi, U. 2010. A single point mutation in the novel PvCesA3 gene confers resistance to the carboxylic acid amide fungicide mandipropamid in Plasmopara viticola. Fungal Genet. Biol. 47:499-510.

Boevink, P. C., McLellan, H., Gilroy, E. M., Naqvi, S., He, Q., Yang, L. N., Wang, X. D., Turnbull, D., Armstrong, M. R., Tian, Z. D., and Birch, P. R. J. 2016. Oomycetes seek help from the plant: Phytophthora infestans effectors target host susceptibility factors. Mol. Plant 9:636-638.

Bos, J. I. B., Armstrong, M. R., Gilroy, E. M., Boevink, P. C., Hein, I., Taylor, R. M., Tian, Z. D., Engelhardt, S., Vetukuri, R. R., Harrower, B., Dixelius, C., Bryan, G., Sadanandom, A., Whisson, S. C., Kamoun, S., and Birch, 
P. R. J. 2010. Phytophthora infestans effector Avr3a is essential for virulence and manipulates plant immunity by stabilizing host E3 ligase CMPG1. Proc. Natl. Acad. Sci. USA 107:9909-9914.

Brunner, F., Rosahl, S., Lee, J., Rudd, J. J., Geiler, C., Kauppinen, S., Rasmussen, G., Scheel, D., and Nuernberger, T. 2002. Pep-13, a plant defense-inducing pathogen-associated pattern from Phytophthora transglutaminases. EMBO J. 21:6681-6688.

Cai, M., Miao, J. Q., Song, X., Lin, D., Bi, Y., Chen, L., Liu, X. L., and Tyler, B. M. 2016. C239s mutation in the beta-tubulin of Phytophthora sojae confers resistance to zoxamide. Front. Microbiol. 7:762.

Childers, R., Danies, G., Myers, K. L., Fei, Z., Small, I. M., and Fry, W. 2014. Acquired resistance to mefenoxam in sensitive isolates of Phytophthora infestans. Phytopathology 105:342-349.

Chowdappa, P., Kumar, N. B. J., Madhura, S., Kumar, M. S. P., Myers, K. L., Fry, W. E., Squires, J. N., and Cooke, D. E. L. 2013. Emergence of 13_a2 blue lineage of Phytophthora infestans was responsible for severe outbreaks of late blight on tomato in south-west india. J. Phytopathol. 161:49-58.

Daggett, S. S., Gotz, E., and Therrien, C. D. 1993. Phenotypic changes in populations of Phytophthora infestans from eastern Germany. Phytopathology 83:319-323.

Dahlin, P., Srivastava, V., Ekengren, S., Mckee, L. S., and Bulone, V. 2017. Comparative analysis of sterol acquisition in the oomycetes Saprolegnia parasitica and Phytophthora infestans. PLoS One 12:e0170873.

Dandurand, L. M., Knudsen, G. R., and Eberlein, C. V. 2006. Susceptibility of five nightshade (Solanum) species to Phytophthora infestans. Am. J. Potato Res. 83:205-210.

Daniel, B., Konrad, B., Toplak, M., Lahham, M., Messenlehner, J., Winkler, A., and Macheroux, P. 2017. The family of berberine bridge enzyme-like enzymes: A treasure-trove of oxidative reactions. Arch. Biochem. Biophys. 632:88-103

Danies, G., Small, I. M., Myers, K., Childers, R., and Fry, W. E. 2013. Phenotypic characterization of recent clonal lineages of Phytophthora infestans in the United States. Plant Dis. 97:873-881.

Davidse, L. C., Looijen, D., Turkensteen, L. J., and Vanderwal, D. 1981. Occurrence of metalaxyl-resistant strains of Phytophthora infestans in Dutch potato fields. Neth. J. Plant Pathol. 87:65-68.

Dong, S. M., Raffaele, S., and Kamoun, S. 2015. The two-speed genomes of filamentous pathogens: Waltz with plants. Curr. Opin. Genet. Dev. 35: 57-65

Dong, S. M., Stam, R., Cano, L. M., Song, J., Sklenar, J., Yoshida, K., Bozkurt, T. O., Oliva, R., Liu, Z. Y., Tian, M. Y., Win, J., Banfield, M. J., Jones, A. M. E., van der Hoorn, R. A. L., and Kamoun, S. 2014. Effector specialization in a lineage of the Irish potato famine pathogen. Science 343: $552-555$

Du, J., and Vleeshouwers, V. G. A. A. 2014. The do's and don'ts of effectoromics. Pages 257-268 in: Plant-Pathogen Interactions: Methods and Protocols, 2nd ed. Humana Press, New York.

Duncan, J. M. 1985. Effect of fungicides on survival, infectivity and germination of Phytophthora fragariae oospores. Trans. Br. Mycol. Soc. 85: 585-593.

Frost, K. E., Johnson, A. C. S., and Gevens, A. J. 2016. Survival of isolates of the US-22, US-23, and US-24 clonal lineages of Phytophthora infestans by asexual means in tomato seed at cold temperatures. Plant Dis. 100: 180-187.

Fry, W. E., Birch, P. R. J., Judelson, H. S., Grünwald, N. J., Danies, G., Everts, K. L., Gevens, A. J., Gugino, B. K., Johnson, D. A., Johnsone, S. B., McGrath, M. T., Myers, K. L., Ristaino, J. B., Roberts, P. D., Secor, G., and Smart, C. D. 2015. Five reasons to consider Phytophthora infestans a reemerging pathogen. Phytopathology 105:966-981.

Fry, W. E., McGrath, M. T., Seaman, A., Zitter, T. A., McLeod, A., Danies, G., Small, I. M., Myers, K., Everts, K., Gevens, A. J., Gugino, B. K., Johnson, S. B., Judelson, H., Ristaino, J., Roberts, R., Secor, G., Seebold, K., Snover-Clift, K., Wyenandt, A., Grünwald, N. J., and Smart, C. D. 2013. The 2009 late blight pandemic in the eastern United States-Causes and results. Plant Dis. 97:296-306.

Gavino, P. D., Smart, C. D., Sandrock, R. W., Miller, J. S., Hamm, P. B., Lee, T. Y., Davis, R. M., and Fry, W. E. 2000. Implications of sexual reproduction for Phytophthora infestans in the United States: Generation of an aggressive lineage. Plant Dis. 84:731-735.

Gees, R., and Hohl, H. R. 1988. Cytological comparison of specific (R3) and general resistance to late blight in potato leaf tissue. Phytopathology 78: 350-357.

Gijzen, M., and Nurnberger, T. 2006. Nep1-like proteins from plant pathogens: Recruitment and diversification of the NPP1 domain across taxa. Phytochemistry 67:1800-1807.

Goss, E. M., Press, C. M., and Grünwald, N. J. 2013. Evolution of RXLR-class effectors in the oomycete plant pathogen Phytophthora ramorum. PLoS One 8:e79347.
Granke, L. L., Windstam, S. T., Hoch, H. C., Smart, C. D., and Hausbeck, M. K. 2009. Dispersal and movement mechanisms of Phytophthora capsici sporangia. Phytopathology 99:1258-1264.

Groves, C. T., and Ristaino, J. B. 2000. Commercial fungicide formulations induce in vitro oospore formation and phenotypic change in mating type in Phytophthora infestans. Phytopathology 90:1201-1208.

Grünwald, N. J., and Flier, W. G. 2005. The biology of Phytophthora infestans at its center of origin. Annu. Rev. Phytopathol. 43:171-190.

Grünwald, N. J., Sturbaum, A. K., Montes, G. R., Serrano, E. G., Lozoya-Saldana, H., and Fry, W. E. 2006. Selection for fungicide resistance within a growing season in field populations of Phytophthora infestans at the center of origin. Phytopathology 96:1397-1403.

Halterman, D. A., Chen, Y., Sopee, J., Berduo-Sandoval, J., and Sanchez-Perez, A. 2010. Competition between Phytophthora infestans effectors leads to increased aggressiveness on plants containing broadspectrum late blight resistance. PLoS One 5:e10536.

Halterman, D. A., Kramer, L. C., Wielgus, S., and Jiang, J. 2008. Performance of transgenic potato containing the late blight resistance gene $R B$. Plant Dis. 92:339-343.

Harnish, W. N. 1965. Effect of light on production of oospores and sporangia in species of Phytophthora. Mycologia 57:85-90.

Haverkort, A. J., Struik, P. C., Visser, R. G. F., and Jacobsen, E. 2009. Applied biotechnology to combat late blight in potato caused by Phytophthora infestans. Potato Res. 52:249-264.

Hirst, J. M. 1953. Changes in atmospheric spore content: Diurnal periodicity and the effects of weather. Trans. Br. Mycol. Soc. 36:375-393.

Jansky, S. H., Charkowski, A. O., Douches, D. S., Gusmini, G., Richael, C., Bethke, P. C., Spooner, D. M., Novy, R. G., De Jong, H., De Jong, W. S., Bamberg, J. B., Thompson, A. L., Bizimungu, B., Holm, D. G., Brown, C. R., Haynes, K. G., Sathuvalli, V. R., Veilleux, R. E., Miller, J. C., Bradeen, J. M., and Jiang, J. M. 2016. Reinventing potato as a diploid inbred line-based crop. Crop Sci. 56:1412-1422.

Judelson, H. S. 1996. Genetic and physical variability at the mating type locus of the oomycete, Phytophthora infestans. Genetics 144:1005-1013.

Judelson, H. S. 2007. Sexual reproduction in plant pathogenic oomycetes. Pages 445-458 in: Sex in fungi, molecular determination and evolutionary implications J. Heitman. J. Kronstad, J. Taylor, and L. Casselton, eds. ASM press, Washington, DC.

Judelson, H. S., Narayan, R. D., Ah-Fong, A. M., and Kim, K. S. 2009. Gene expression changes during asexual sporulation by the late blight agent Phytophthora infestans occur in discrete temporal stages. Mol. Genet. Genomics 281:193-206.

Judelson, H. S., and Roberts, S. 1999. Multiple loci determining insensitivity to phenylamide fungicides in Phytophthora infestans. Phytopathology 89:754-760.

Judelson, H. S., and Senthil, G. S. 2006. Investigating the role of ABC transporters in multifungicide insensitivity in Phytophthora infestans. Mol. Plant Pathol. 7:17-29.

Kagda, M. 2017. Insight into the dynamic metabolism of Phytophthora infestans. Ph.D. thesis. University of California, Riverside.

Lehtinen, A., and Hannukkala, A. 2004. Oospores of Phytophthora infestans in soil provide an important new source of primary inoculum in Finland. Agric. Food Sci. 13:399-410.

Lenarcic, T., Albert, I., Bohm, H., Hodnik, V., Pirc, K., Zavec, A. B., Podobnik, M., Pahovnik, D., Zagar, E., Pruitt, R., Greimel, P., Yamaji-Hasegawa, A., Kobayashi, T., Zienkiewicz, A., Gomann, J., Mortimer, J. C., Fang, L., Mamode-Cassim, A., Deleu, M., Lins, L., Oecking, C., Feussner, I., Mongrand, S., Anderluh, G., and Nurnberger, T. 2017. Eudicot plantspecific sphingolipids determine host selectivity of microbial NLP cytolysins. Science 358:1431-1434.

Li, Y., Shen, H., Zhou, Q., Qian, K., van der Lee, T., and Huang, S. W. 2017. Changing ploidy as a strategy: The Irish potato famine pathogen shifts ploidy in relation to its sexuality. Mol. Plant-Microbe Interact. 30:45-52.

Li, Y., van der Lee, T., Zhu, J. H., Jin, G. H., Lan, C. Z., Zhu, S. X., Zhang, R. F., Liu, B. W., Zhao, Z. J., Kessel, G., Huang, S. W., and Jacobsen, E. 2013. Population structure of Phytophthora infestans in China - geographic clusters and presence of the EU genotype blue_13. Plant Pathol. 62: 932-942.

Liu, T. L., Song, T. Q., Zhang, X., Yuan, H. B., Su, L. M., Li, W. L., Xu, J., Liu, S. H., Chen, L. L., Chen, T. Z., Zhang, M. X., Gu, L. C., Zhang, B. L., and Dou, D. L. 2014. Unconventionally secreted effectors of two filamentous pathogens target plant salicylate biosynthesis. Nat. Commun. 5:4686.

Lu, Y. J., Schornack, S., Spallek, T., Geldner, N., Chory, J., Schellmann, S., Schumacher, K., Kamoun, S., and Robatzek, S. 2012. Patterns of plant subcellular responses to successful oomycete infections reveal differences in host cell reprogramming and endocytic trafficking. Cell. Microbiol. 14: 682-697.

Malcolmson, J. F. 1969. Races of Phytophthora infestans occurring in Great Britain. Trans. Br. Mycol. Soc. 53:417-423. 
Maltese, C. E., Conigliaro, G., and Shaw, D. S. 1995. The development of sporangia of Phytophthora infestans. Mycol. Res. 99:1175-1181.

Mariduena-Zavala, M. G., Freire-Penaherrera, A., Cevallos-Cevallos, J. M., and Peralta, E. L. 2017. Gc-ms metabolite profiling of Phytophthora infestans resistant to metalaxyl. Eur. J. Plant Pathol. 149:563-574.

Mariette, N., Androdias, A., Mabon, R., Corbiere, R., Marquer, B., Montarry, J., and Andrivon, D. 2016. Local adaptation to temperature in populations and clonal lineages of the Irish potato famine pathogen Phytophthora infestans. Ecol. Evol. 6:6320-6331.

Matson, M. E. H., Small, I. M., Fry, W. E., and Judelson, H. S. 2015. Metalaxyl resistance in Phytophthora infestans: Assessing role of RPA190 gene and diversity within clonal lineages. Phytopathology 105:1594-1600.

Miao, J. Q., Cai, M., Dong, X., Liu, L., Lin, D., Zhang, C., Pang, Z. L., and Liu, X. L. 2016. Resistance assessment for oxathiapiprolin in Phytophthora capsici and the detection of a point mutation (G769G) in PcOrp1 that confers resistance. Front. Microbiol. 7:615.

Mizubuti, E. S. G., Aylor, D. E., and Fry, W. E. 2000. Survival of Phytophthora infestans sporangia exposed to solar radiation. Phytopathology 90:78-84.

Pang, Z. L., Chen, L., Miao, J. Q., Wang, Z. W., Bulone, V., and Liu, X. L. 2015. Proteomic profile of the plant-pathogenic oomycete Phytophthora capsici in response to the fungicide pyrimorph. Proteomics 15:2972-2982.

Porter, L. D., Dasguipta, N., and Johnson, D. A. 2005. Effects of tuber depth and soil moisture on infection of potato tubers in soil by Phytophthora infestans. Plant Dis. 89:146-152.

Qutob, D., Patrick Chapman, B., and Gijzen, M. 2013. Transgenerational gene silencing causes gain of virulence in a plant pathogen. Nat. Commun. 4:1349.

Raffaele, S., Farrer, R. A., Cano, L. M., Studholme, D. J., MacLean, D., Thines, M., Jiang, R. H., Zody, M. C., Kunjeti, S. G., Donofrio, N. M., Meyers, B. C., Nusbaum, C., and Kamoun, S. 2010b. Genome evolution following host jumps in the Irish potato famine pathogen lineage. Science 330:1540-1543.

Raffaele, S., Win, J., Cano, L. M., and Kamoun, S. 2010a. Analyses of genome architecture and gene expression reveal novel candidate virulence factors in the secretome of Phytophthora infestans. BMC Genomics 11:637.

Randall, E., Young, V., Sierotzki, H., Scalliet, G., Birch, P. R. J., Cooke, D. E. L., Csukai, M., and Whisson, S. C. 2014. Sequence diversity in the large subunit of rna polymerase i contributes to mefenoxam insensitivity in Phytophthora infestans. Mol. Plant Pathol. 15:664-676.

Rietman, H., Bijsterbosch, G., Cano, L. M., Lee, H. R., Vossen, J. H., Jacobsen, E., Visser, R. G. F., Kamoun, S., and Vleeshouwers, V. G. A. A. 2012. Qualitative and quantitative late blight resistance in the potato cultivar Sarpo Mira is determined by the perception of five distinct RXLR effectors. Mol. Plant-Microbe Interact. 25:910-919.

Rodriguez-Moreno, L., Song, Y., and Thomma, B. P. H. J. 2017. Transfer and engineering of immune receptors to improve recognition capacities in crops. Curr. Opin. Plant Biol. 38:42-49.

Roper, M., Pepper, R. E., Brenner, M. P., and Pringle, A. 2008. Explosively launched spores of ascomycete fungi have drag-minimizing shapes. Proc. Natl. Acad. Sci. USA 105:20583-20588.

Saville, A., Graham, K., Grünwald, N., Myers, K., Fry, W. E., and Ristaino, J. B. 2015. Fungicide sensitivity of us genotypes of Phytophthora infestans (Mont.) de Bary to six oomycete-targeted compounds. Plant Dis. 99:659-666.

Savory, F., Leonard, G., and Richards, T. A. 2015. The role of horizontal gene transfer in the evolution of the oomycetes. PLoS Pathog 11:e1004805.

Schepers, H. T. A. M., Kessel, G. J. T., Lucca, F., Förch, M. G., van den Bosch, G. B. M., Topper, C. G., and Evenhuis, A. 2018. Reduced efficacy of fluazinam against Phytophthora infestans in the Netherlands. Eur. J. Plant Pathol. doi.org/10.1007/s10658-018-1430-y
Sharpee, W. C., and Dean, R. A. 2016. Form and function of fungal and oomycete effectors. Fungal Biol. Rev. 30:62-73.

Small, I. M., Joseph, L., and Fry, W. E. 2015. Development and implementation of the blightpro decision support system for potato and tomato late blight management. Comput. Electron. Agric. 115:57-65.

Song, T. Q., Ma, Z. C., Shen, D. Y., Li, Q., Li, W. L., Su, L. M., Ye, T. Y., Zhang, M. X., Wang, Y. C., and Dou, D. L. 2015. An oomycete CRN effector reprograms expression of plant HSP genes by targeting their promoters. PLoS Pathog. 11:e1005348.

Streubel, J., Pesce, C., Hutin, M., Koebnik, R., Boch, J., and Szurek, B. 2013. Five phylogenetically close rice sweet genes confer TAL effectormediated susceptibility to Xanthomonas oryzae pv. oryzae. New Phytol. 200:808-819.

Tani, S., and Judelson, H. S. 2006. Activation of zoosporogenesis-specific genes in Phytophthora infestans involves a 7-nucleotide promoter motif and cold-induced membrane rigidity. Eukaryot. Cell 5:745-752.

Todd, R. T., Forche, A., and Selmecki, A. 2017. Ploidy variation in fungi: Polyploidy, aneuploidy, and genome evolution. Microbiol Spectrrum 5(4): FUNK-0051-2016.

Turkensteen, L. J. 1993. Durable resistance of potatoes against Phytophthora infestans. Curr. Plant Sci. Biotechnol. 18:115-124.

Turkensteen, L. J., Flier, W. G., Wanningen, R., and Mulder, A. 2000. Production, survival and infectivity of oospores of Phytophthora infestans. Plant Pathol. 49:688-696.

Vetukuri, R. R., Asman, A. K., Tellgren-Roth, C., Jahan, S. N., Reimegard, J., Fogelqvist, J., Savenkov, E., Soderbom, F., Avrova, A. O., Whisson, S. C., and Dixelius, C. 2012. Evidence for small RNAs homologous to effectorencoding genes and transposable elements in the oomycete Phytophthora infestans. PLoS One 7:e51399.

Walker, C., and van West, P. 2007. Zoospore development in the oomycetes. Fungal Biol. Rev. 21:10-18.

Wang, S., Boevink, P. C., Welsh, L., Zhang, R., Whisson, S. C., and Birch, P. R. J. 2017. Delivery of cytoplasmic and apoplast effectors from Phytophthora infestans haustoria by distinct secretion pathways. New Phytol. 216:205-215.

Win, J., Krasileva, K. V., Kamoun, S., Shirasu, K., Staskawicz, B. J., and Banfield, M. J. 2012. Sequence divergent RXLR effectors share a structural fold conserved across plant pathogenic oomycete species. PLoS Pathog. 8:e1002400.

Wu, D. L., Navet, N., Liu, Y. C., Uchida, J., and Tian, M. Y. 2016. Establishment of a simple and efficient Agrobacterium-mediated transformation system for Phytophthora palmivora. BMC Microbiol. 16:204.

Xiang, Q. J., and Judelson, H. S. 2014. Myb transcription factors and light regulate sporulation in the oomycete Phytophthora infestans. PLoS One 9:e92086.

Yin, J. L., Gu, B., Huang, G. Y., Tian, Y., Quan, J. L., Lindqvist-Kreuze, H., and Shan, W. X. 2017. Conserved RXLR effector genes of Phytophthora infestans expressed at the early stage of potato infection are suppressive to host defense. Front. Plant Sci. 8:2155.

Yoshida, K., Schuenemann, V. J., Cano, L. M., Pais, M., Mishra, B., Sharma, R., Lanz, C., Martin, F. N., Kamoun, S., Krause, J., Thines, M., Weigel, D., and Burbano, H. A. 2013. The rise and fall of the Phytophthora infestans lineage that triggered the Irish potato famine. eLife 2:731.

Zeier, J. 2013. New insights into the regulation of plant immunity by amino acid metabolic pathways. Plant Cell Environ. 36:2085-2103.

Zhu, W., Shen, L. L., Fang, Z. G., Yang, L. N., Zhang, J. F., Sun, D. L., and Zhan, J. S. 2016. Increased frequency of self-fertile isolates in Phytophthora infestans may attribute to their higher fitness relative to the A1 isolates. Sci. Rep. 6:29428.

Zipfel, C. 2014. Plant pattern-recognition receptors. Trends Immunol. 35: 345-351. 